\title{
LIFE AFTER ICU: THE AFTERCARE OF PATIENTS AND THEIR FAMILIES
}

\author{
Debi Wearing, Sister, Intensive Care \\ Royal Lancaster Infirmary
}

\section{BACKGROUND}

Follow-up after intensive care can include care for the patient and/or relatives following a live discharge or the care of bereaved relatives following a patient's death. There is increasing evidence to show that many patients experience physical and psychological problems following intensive care, such as pain, sleep disturbances, depression and posttraumatic stress. Although these effects have been well documented, there are few studies on what the long-term effects are. The research that has been done suggests that problems persist. Patients may have little or no memory of their stay in intensive care, but can experience nightmares, panic attacks, depression and social isolation. While followup has been limited, evidence suggests that support postintensive care does work and can improve the speed and quality of recovery ${ }^{(1,2)}$.

Nationally established follow-up services are few at present. This is changing following the publication of the Department of Health document 'A Review of Adult Critical Care Services'. The government recommends that follow-up be introduced as part of the outreach team, and many ICUs are now working to try to establish a follow-up service, as we are at Lancaster.

\section{FOLLOW-UP OF PATIENTS}

Who should follow up patients? Should intensive care staff need to offer follow-up services when there are networks already available to patients on discharge into the community? Research has shown reluctance by patients to use these services, as many still perceive a stigma attached to asking for professional help or realising that help exists ${ }^{(3)}$. Using intensive care staff to provide follow-up makes use of the existing bond, knowledge of the patient's illness, care and family dynamics, and also an understanding of what intensive care is like. This provides a foundation for recovery. The caring relationship which can develop between nurses and patients provides a degree of security and comfort which may help the patient to overcome some of the traumatic experiences of intensive care. Patients are used to the idea of attending outpatient clinics following discharge from hospital, although some patients do develop a fear of hospitals and may be reluctant to return unnecessarily. This is why some clinics are run out of the hospital, and indeed some visit the patients at home $\mathrm{e}^{(1,4)}$.

Follow-up should start with patients following their discharge to the general ward. Many patients find the transfer to the ward from intensive care traumatic. Although often seen as a sign of their progress, they often express concern about the sudden and dramatic change in the level of attention they receive as they leave an area of one-to-one nursing, and describe it as stressful, confusing and tiring ${ }^{(5.6)}$.
Visits from ICU staff help to maintain the bond between patient and nurse and can ease anxiety following transfer to the ward. They also provide a starting point for assessing the patients; this is continued after hospital discharge when patients can be reviewed in the critical care follow-up clinic. This enables an evaluation of the patient's medical condition with the chance to refer on to other specialists. The patient may also be assessed for psychological problems such as depression and post-traumatic stress.

\section{FOLLOW-UP OF FAMILIES}

Should intensive care staff offer support to relatives after a patient's death? Dealing with bereaved relatives is unfortunately commonplace in intensive care and there is evidence to suggest that relatives' response to bereavement is affected by the quality of the care given to both the deceased and themselves. It is recognised that providing some form of support to relatives is part of the intensive care nurse's role ${ }^{(7.89)}$.

Grief and mourning are natural processes we all go through, so why should anybody need help? Although many people do work through the grieving process within their own care network of family and friends, research shows that counselling support can help facilitate normal grief to a healthy completion within a reasonable time-frame ${ }^{(10,11)}$. Grief is recognised to have many physiological and psychological effects with significant morbidity, and must be worked through if a person is to maintain a reasonably happy existence and return to a functioning role in society. For a small number of people grief can become abnormal, with overwhelming reactions and severe adjustment problems as they become stuck in the grieving process. Abnormal grief is more likely to occur in people from high-risk groups, such as those who have been involved in a sudden or violent death, a common scenario in intensive care ${ }^{(10,11,12)}$.

The support offered may be as simple as providing time for the relatives. We give the family and friends the opportunity to sit with the deceased, and stay with them so they have the opportunity to talk about their immediate feelings if they so wish. We always offer them the chance to discuss any concerns they may have regarding the nursing and medical care given. This can then extend to providing literature on bereavement, advice on what to do after a death, contact addresses of support organisations or offering full bereavement counselling services.

\section{OUR AIMS}

The trust aims to develop an outreach service. The service this will provide depends on future funding and staff resources. At RLI we already have some services in place and we are working to research and develop these further. 
There is a newly formed bereavement group, who have produced a bereavement resource file for staff. This includes literature on bereavement, breaking bad news and cultural differences as well as providing data on the availability of study days for the nursing and medical staff. The group also follows up bereaved relatives. We don't offer a counselling service, but do offer the opportunity for the family to come back and discuss any concerns they may have about the nursing and medical care their relative received on ICU. When a patient dies we record in a diary details of their ICU stay, cause of death and next of kin details. One month after the death a card is sent to the next of kin with details of our follow-up service and of other local and national help networks that are available, with contact addresses. This is repeated at 12 months. In the early stages of this process the verbal and written feedback from relatives has been positive, and has encouraged us to continue the group.

Developing services for patients and relatives is ongoing. There is an information booklet given to the patient's family members which introduces the ICU to them and gives an outline of the intensive care process and also the facilities available to them. This booklet contains a questionnaire which gives them the opportunity to comment on aspects of both their and the patient's care. This is useful in highlighting areas that we needed to improve.

Intensive care staff often visit patients, particularly those who have had a long stay on the unit, during their recovery on the general ward. Patients who have asked for information about their care have had the opportunity to go through their nursing notes in detail and discuss aspects of their care that they are unsure about.

Follow-up for patients and relatives after discharge from ICU in Lancaster is at present only on an informal basis. Though eventually we would like to establish a follow-up clinic for patients and relatives who come through our ICU, this is a long way in the future and requires significant resources. We are still at the fact-finding stage, which has included much letter writing and a visit to the established clinic at Whiston. This follow-up clinic has been running for 10 years and the staff there were able to show us what they do. However there are projects locally currently under development, which we hope to introduce within the next 12 months. A booklet is being developed to give to patients and relatives on discharge to the ward. It will give advice on the common problems and worries expressed by patients as identified in our research. It will cover how care on the ward differs from ICU, as well as physiotherapy, sleeping, eating, mood changes etc. Patients will be visited on the ward, giving them the opportunity to talk about any concerns they may have, as well as being asked to complete a questionnaire. The questionnaire is in a format that can be used for audit, is voluntary and will cover what they feel about the care they received and how we can improve our service.

It will also cover other aspects, such as what the patients remember about their stay, if they are experiencing recurrent nightmares and other general concerns. They will also be asked if they would like to have the opportunity to talk in detail about any aspects of their time in intensive care to one of our nurses. We will then, if requested, be able to visit them giving them a brief summary of significant events which occurred, with explanations and information. Poor recall of their illness and care causes many patients to have misconceptions, feel frustrated and have unrealistic goals about their recovery. Giving them the time to talk throughout their stay and having time to answer questions will hopefully give them a greater understanding. This service will also be offered to family members if the patient is happy to involve them.

In conjunction with this we will introduce patient diaries. This idea is supported by work done by Carl Backmann in Sweden, where the use of diaries has had a positive response from patients and families. The diaries would be available for staff, family and friends to record events, feelings and photographs of the patient's stay. The diary follows the patients to the ward and is available for them to read when they feel able. This will give them an insight into both their stay and the feelings of their family.

As our service expands we would obviously have the expectation of liaising with the patient's GP in the aftercare, enabling us to provide a holistic approach as suited to each individual.

In conclusion, with the development of our outreach service including follow-up, we hope to continue to develop and improve the aftercare we provide for both our patients and families in the future.

\section{REFERENCES}

1 Griffths RD, Jones C. Recovery from intensive care. Br Med J 1999;319:427-29

2 Jones C, Griffiths RD, Macmillian R. Psychological problems occurring after intensive care. $\mathrm{Br} \mathrm{J}$ Intens Care 1994;176-79

3 Maddox M, Dunn SV, Pretty LE. Psychological recovery following ICU. Experiences and influences upon discharge into the community. Intens Crit Care Nursing 2001;Feb17:615

4 Granberg A, Bergman C, Engberg I, Lunberg D. Patients' experience of being critically ill or severely injured, and cared for in an ICU in relation to the ICU syndrome Part 1 Intens Crit Care Nursing 1998; Dec 14:294-30

5 Odell M. The patient's thoughts and feelings about their transfer from intensive care to the general ward. J Adv Nursing 2000; Feb 3:322-9

6 Leith BA. Patients and family member's perceptions of transfer from Intensive care. Heart and Lung 1999;MayJune: $210-8$

7 Campbell M, Thill M. Bereavement follow-up for families after death in the intensive care. Crit Care Med 2000;28(4):1252-53

8 Hill C. Evaluating the quality of after care. Nursing Standard 1997; 12(8):37-9

9 Jackson I. Critical care nurse's perceptions of a bereavement follow up service. Intens and Crit Care Nursing 1996; 12(1):2-11

10 Stroebe W, Stroebe M, Hansson R. (eds) Handbook of Bereavement, Theory, Research and Intervention. 1993 Cambridge University Press London

11 Farrell P. The limitations of current theories in understanding bereavement and grief. Counselling 1999; 10:11-13

12 Dickenson D, Johnson M. (eds) Death, dying and bereavement. 1993 Sage Publications London 